\title{
Thermal characteristics of temperature-controlled electrochemical microdevices
}

\author{
Nicholas M. Contento and Steve Semancik
}

Bioprocess Measurements Group, National Institute of Standards and Technology, Gaithersburg,

MD 20899 


\section{Abstract}

The development of novel, miniaturized sensing systems is driven by the demand for better and faster chemical measurements with lower power consumption and smaller sample sizes. Emerging miniature sensors, or microsensors, also offer rapid thermal and diffusive transport characteristics. For instance, temperature changes, during both heating and cooling, can be achieved on micrometer-scale surfaces much more rapidly than on bulk, macro-scale surfaces. While these rapid thermal characteristics have been most successfully exploited to date in gasphase sensing devices, the prospect of developing analogous microfabricated, temperaturecontrolled microsensors for use in aqueous, or solution-phase, environments has been less explored. In this work, electrodes with underlying microheaters were designed and fabricated, and thermal characterization was performed using temperature imaging, transient temperature measurements, and theoretical modeling to determine temperature distributions and thermal response times in both gas- and solution-phase environments. These results will guide the development of solution-phase electrochemical sensors. Temperature-controlled electrochemical characterization was performed using cyclic voltammetry of a model analyte, hexaamineruthenium(III) chloride, to demonstrate the use of the multilayer, microfabricated devices, which consisted of a gold disk electrode and an underlying microheater. Electrochemical signals were enhanced by up to a factor of three at elevated temperatures (up to $\left.81{ }^{\circ} \mathrm{C}\right)$ compared to the those measured at room temperature $\left(21^{\circ} \mathrm{C}\right)$. This improved signal at elevated temperatures was explained by finite element method calculations that accounted for both temperature-dependent diffusion and thermal convection near the heated electrode surface.

Keywords: microheater; temperature; electrochemistry; thermal imaging; cyclic voltammetry 


\section{Introduction}

The need for high quality, real-time analytical data drives the continued development of miniaturized chemical and physical sensors. Microsensors with improved performance characteristics, compared to their macro-scale counterparts, can be built using standard microfabrication techniques, enabling novel technologies for process monitoring and interactive consumer electronics. These microfabrication techniques are also compatible with the development of sensor array platforms for high throughput (bio)chemical detection and characterization methods. Aside from the advantages of lower cost and increased portability, micro-scale systems have unique thermal and diffusive transport properties that allow unprecedented levels of control over transient properties of sensing surfaces. Here we take advantage of the relative speed and efficiency of thermal transport across small characteristic dimensions ( $\lesssim 100 \mu \mathrm{m})$ to build microfabricated devices containing electrodes and proximal resistive microheaters.

Rapid temperature control has been demonstrated to be a useful tool, yielding increased chemical information in gas-phase measurements. Temperature-controlled gas sensors (often termed microhotplate devices), which benefit from improved measurement speed, high signal, and good selectivity [1-3], have been in development since the mid 1990's [4-6] and have recently reached various stages of commercialization [7]. These devices have shown promise in applications for hazardous gas detection [8,9], air quality monitoring [10,11], artificial olfaction [12], and breath analysis [13]. A major benefit of microheater-based sensors is their ability to perform transient analyses using temperature programming in the time domain. Data rich, transient sensor responses can be interpreted using principle component analyses, machine learning techniques, and temperature feedback routines to achieve improved sensitivity and 
selectivity even in unfamiliar sample backgrounds [14-16]. By extending microheater-based sensing into solution-phase samples, related, previously impossible transient studies would become available for aqueous chemical and biochemical measurements.

Microheaters have been used independently (i.e., without a chemical sensor or electrode) for temperature control in aqueous systems for a range of studies including bubble nucleation and growth [17,18], DNA amplification [19-21], cell culture and growth [22,23], and other microfluidic applications [24]. However, microheaters have only infrequently been coupled to solution-phase sensors. Fortunately, a few examples of solution-phase, microheater-based sensing exemplify the anticipated benefits of developing this technology. In studies by Arata et al., a microheater was combined with optical measurements to demonstrate the enhanced activity of an immobilized enzyme and determine the rate of DNA-intercalator interactions during short duration temperature pulses $[25,26]$. Haesik et al. combined microheater control with a sensing electrode to produce temperature controlled electrodes that were built over insulated cavities on a $\mathrm{Si}$ wafer [27]. Shen et al. recently built heated electrodes on more thermally insulating $\mathrm{SiO}_{2}$ substrates to perform electrochemical measurements of the temperature-dependent melting of matched and mismatched DNA probe-target pairs [28]. These less fabrication-intensive $\mathrm{SiO}_{2}-$ based devices achieved similar operating temperatures as those of the insulated cavity devices at modest heating powers. However, the detailed thermal characteristics, e.g. the temperature distributions and thermal response times, of these microfabricated $\mathrm{SiO}_{2}$-based electrodes have not been studied.

A systematic thermal characterization of $\mathrm{SiO}_{2}$-based heated electrodes is presented in this work to demonstrate their potential as an emerging tool in the field of thermoelectrochemistry [29]. Traditionally, electrode heating in thermoelectrochemistry has been achieved using a 
variety of external sources like lasers [30], light beams [31], and microwaves [32]. The Gründler group pioneered the use of "hot-wire" electrodes, metal wire electrodes across which an AC heating current is applied [33]. Heated electrodes can access enhanced reaction kinetics, faster diffusion, and increased mixing through induced thermal convection [34,35], and commercial systems have recently become available for their operation [36].

The microheater-based electrodes presented in this work have several potential advantages compared to other heating mechanisms: (1) The microheater eliminates the need for external hardware such as light or microwave heat sources. (2) The small $(<1 \mu \mathrm{m})$ separation distance between the electrode and microheater enables rapid temperature control, similar to that achieved at directly heated electrodes, e.g., "hot-wire" electrodes, while the sensing and heating electronics of the insulated microheater-based electrodes are effectively decoupled. (3) The microheater can be used as a resistance thermometer for real-time temperature monitoring. (4) Temperature gradients in solution and temperature uniformity at an electrode's surface can be more effectively controlled by selectively controlling the relative sizes of the microheater and electrode during design and fabrication than might otherwise be possible with directly heated systems. (5) Finally, the development of temperature-controlled sensor arrays for high throughput applications will be enabled by the relative ease of measuring individually addressable heating and sensing signals and by the use of established microfabrication techniques for device fabrication. The characterization performed in this work will guide the construction of integrated electrode arrays with appropriate thermal characteristics in the future.

Although seemingly straight-forward at the outset, the reliable adaptation of established gas-phase, micro-heater-based sensing paradigms to solution-phase environments has been hindered by several challenges. The high effective thermal load of high heat capacity aqueous 
environments severely decreases heating efficiency, limiting maximum achievable temperatures. Fortunately, a larger temperature range can be achieved by either fabricating insulating vacuum chambers below each electrode or by simply using a more thermally insulating glass, or $\mathrm{SiO}_{2}$, substrate to improve microheater efficiency $[27,28]$.

In order to characterize a microheater-based device for solution-phase measurements, electrodes were fabricated with underlying resistive microheaters using standard microfabrication methods. Their thermal characteristics were examined in both the gas phase and the solution phase using a variety of optical (fluorescence and infrared (IR)), electronic (resistance thermometry), and electrochemical (cyclic voltammetry and open circuit potential) techniques. These experimental results were then compared to theoretical finite element method (FEM) calculations. The heated electrodes were then employed for the detection hexaamineruthenium(III) chloride, a model analyte, using cyclic voltammetry. The temperature dependence of the electrochemical signal was similar to that observed for other heated electrodes and was also in good agreement with FEM calculations of thermal and mass transport in the temperature-controlled system. This work forms a foundation for the ongoing development of temperature-controlled sensor arrays for high-throughput (bio)chemical sensing in the solution phase by establishing the thermal and electrochemical characteristics of these $\mathrm{SiO}_{2}$-based microfabricated devices.

\section{Materials and methods*}

\subsection{Materials}

Microheater controlled electrodes were fabricated on borosilicate glass wafers (Borofloat 33 University Wafer, Boston, MA, USA) with a thickness of $0.5 \mathrm{~mm}$ and diameter of $100 \mathrm{~mm}$. Chemicals and materials used for fabrication included the photoresists, AZ5214E (EMD 
Performance Materials, Darmstadt, Germany) and S1813 (Dow Corning, Midland, MI, USA), and buffered piranha solution (Nanostrip, KMG, Houston, TX, USA) using procedures detailed in Section 2.2.

All chemicals used were of analytical grade purity or better. Potassium phosphate monobasic $\left(\mathrm{KH}_{2} \mathrm{PO}_{4}\right)$, potassium phosphate dibasic $\left(\mathrm{K}_{2} \mathrm{HPO}_{4}\right)$, potassium nitrate $\left(\mathrm{KNO}_{3}\right)$, potassium ferricyanide $\left(\mathrm{K}_{3}\left[\mathrm{Fe}(\mathrm{CN})_{6}\right]\right)$, potassium ferrocyanide $\left(\mathrm{K}_{4}\left[\mathrm{Fe}(\mathrm{CN})_{6}\right]\right)$, rhodamine $\mathrm{b}$, and hexaamineruthenium(III) chloride $\left(\mathrm{Ru}\left(\mathrm{NH}_{3}\right)_{6} \mathrm{Cl}_{3}\right)$ were purchased from Sigma-Aldrich. All solutions were prepared in filtered, deionized water with a resistance of no less than $18 \mathrm{M} \Omega \cdot \mathrm{cm}$.

\subsection{Device fabrication}

Microheater-controlled electrode devices were fabricated using standard microfabrication processes in the cleanroom facility at the National Institute for Standards and Technology (NIST). The procedures followed were similar to those reported by Shen et al. [28], with several modifications. They consisted of sequential rounds of photoresist patterning, metal deposition, insulation $\left(\mathrm{SiO}_{2}\right)$ deposition, and reactive ion etching, as summarized in Fig. 1(a). Microheater patterns were transferred to a piranha-cleaned glass wafer with AZ5214E photoresist in the image reversal mode using a contact aligner (MA8 Suss Microtec, Sunnyvale, CA, USA) according to the manufacturer's instructions. A platinum thin film $(100 \mathrm{~nm})$ was then deposited over the patterned substrate via electron beam evaporation (Denton Vacuum Infinity 22, San Diego, CA, USA) with a titanium adhesion layer $(20 \mathrm{~nm})$. The remaining photoresist was removed by lift-off in Remover PG (MicroChem, Boston, MA, USA). Samples were then rinsed in acetone, isopropanol, and DI water before being dried with nitrogen and cleaned in piranha solution (2 min). An insulating overlayer of $\mathrm{SiO}_{2}$ (at least $600 \mathrm{~nm}$ ) was then deposited using plasma enhanced chemical vapor deposition (PECVD, Unaxis 790 Plasmatherm, Saint 
Petersburg, FL, USA), and electric contact pads were exposed by patterning openings in photoresist, S1813, and performing a reactive ion etch (RIE, Unaxis 790 Plasmatherm, Saint Petersburg, FL, USA). An example of a resulting microheater structure is shown in Fig. 1(b). Similar steps were repeated - photolithography with AZ5214E, e-beam deposition of metal (20 $\mathrm{nm} \mathrm{Cr} / 150 \mathrm{~nm} \mathrm{Au}), \mathrm{PECVD}$ of $\mathrm{SiO}_{2}(600 \mathrm{~nm})$, photolithography with S1813, and RIE of $\mathrm{SiO}_{2}$ overlayer - in order to realize electrical contacts and electrodes and achieve the final device shown in Fig. 1(c). The resulting electrodes were stable throughout the course of the electrochemical measurements performed (Section 2.5), and lift-off of the metallic films was not observed during heating. The electrode shown in Fig. 1(c) was designed to be smaller than the underlying heater in order to reduce the impact of temperature gradients near the edges of the microheater and improve temperature uniformity (see discussion in Section 3.2).

Completed wafers were then diced (DISCO DAD-341, Disco Corporation, Japan) into individual chips containing four microheater-controlled electrodes per approximately $20 \mathrm{~cm}^{2}$ piece. Electrical contact to the microheaters and electrodes was established either using conductive silver epoxy (EMS, Hatfield, PA, USA) or a custom plastic holder with metal clips, which contacted the relatively large $\approx 1 \mathrm{~mm}^{2}$ contact pads.

\subsection{Infrared Thermal Imaging}

IR thermal imaging was performed with a thermal camera (Cedip Jade III, wavelength range: $3.6 \mu \mathrm{m}$ to $5.1 \mu \mathrm{m}$, CEDIP Infrared Systems SA, France) equipped with a high magnification lens (L0120E, f/2, FLIR Systems, Arlington, VA, USA). A temperature-controlled sample holder with micrometer position control was used. A pixel-by-pixel image intensity-totemperature calibration was performed prior to imaging the temperature landscapes generated during the powering of microheaters. This calibration was crucial to reliably measuring the 
temperature of the dissimilar glass and platinum surfaces, and details of the calibration procedure are included in the Supplemental Information. Relatively large microheater elements $\left(\approx 200 \mu \mathrm{m}^{2}\right)$ were imaged, because the smaller devices shown in Fig. 1(b) and 1(c) are near the imaging resolution limit of approximately $15 \mu \mathrm{m}$ to $20 \mu \mathrm{m}$. Videos of powered microheaters were acquired at 60 frames/second.

\subsection{Fluorescent thermal imaging}

In order to image temperature in the solution phase, which is incompatible with IR thermal imaging because of water's strong absorption in the IR region, a fluorescent temperature imaging technique was used, employing the temperature-sensitive fluorescence of a $100 \mu \mathrm{mol} / \mathrm{L}$ rhodamine $b$ solution [37]. The microheater was observed at $10 \times$ magnification (numerical aperture: 0.3 ) under an epifluorescence microscope (Leica DMRX, Leica Microsystems, Wetzlar, Germany) equipped with a rhodamine b filter set (excitation: $545 \mathrm{~nm} / \mathrm{emission}: 610$ $\mathrm{nm})$. Excitation was provided by a mercury arc lamp, while images were captured by a computer-controlled digital camera (Infinity 2, Lumenera Corp., Ottawa, Canada) using the manufacturer's image acquisition software (Infinity Analyze).

Because of the large background fluorescence from solution far from the microheater surface, the temperature indicating solution was filled into a poly(dimethylsiloxane) (Sylgard 184 Kit, Dow Corning Corporation, Midland, MI, USA $)$ microchannel $(h \times w=50 \mu \mathrm{m} \times 500$ $\mu \mathrm{m})$ that was placed above the microheater. Details of the fluorescence-based temperature calibration equation used and microchannel fabrication are included in the Supplemental Information. 


\subsection{Electronics for microheater control and electrochemistry}

Microheaters were controlled with a computer controlled source/measure unit (Agilent B2902A, Agilent Technologies, Santa Clara, CA). Resistance was measured at constant current. Temperature calibrations were performed in a thermostat-fitted oven for several different microheater structures to determine the temperature dependence of resistance. Temperature was measured at low current $(0.5 \mathrm{~mA})$ without measurable self-heating, while the application of higher currents $(>1 \mathrm{~mA})$ caused microheater temperature to increase as indicated by an increase in resistance.

Electrochemical control was achieved using a computer controlled potentiostat (CHI660 CH Instruments Inc, Austin, TX, USA). Open circuit potential (OCP) measurements were performed at different temperatures using an $\mathrm{Ag} / \mathrm{AgCl}$ reference electrode (ET072 eDAQ, Inc., Colorado Springs, $\mathrm{CO}, \mathrm{USA}$ ) in $\approx 40 \mu \mathrm{L}$ of $0.5 \mathrm{~mol} / \mathrm{L} \mathrm{KNO}_{3}, 0.2 \mathrm{~mol} / \mathrm{L}$ potassium phosphate buffer (pH 7), and $10 \mathrm{mmol} / \mathrm{L} \mathrm{K}_{3}\left[\mathrm{Fe}(\mathrm{CN})_{6}\right] / \mathrm{K}_{3}\left[\mathrm{Fe}(\mathrm{CN})_{6}\right]$ (1:1). Cyclic voltammetry was performed in $\approx 40 \mu \mathrm{L}$ droplet of $10 \mathrm{mmol} / \mathrm{L} \mathrm{Ru}\left(\mathrm{NH}_{3}\right)_{6} \mathrm{Cl}_{3}$ with $0.5 \mathrm{~mol} / \mathrm{L} \mathrm{KNO}_{3}$ and $0.2 \mathrm{~mol} / \mathrm{L}$ potassium phosphate buffer ( $\mathrm{pH} 7)$, while the microheater was heated to different temperatures. The results reported here were recorded at $100 \mathrm{mV} / \mathrm{s}$ using the same $\mathrm{Ag} / \mathrm{AgCl}$ reference electrode described above and a platinum wire counter electrode.

\subsection{Finite element method calculations}

FEM calculations of relevant heat and mass transport phenomena within the microheater systems was performed using Comsol Multiphysics version 4.4 (Comsol, Stockholm, Sweden). A two dimensional, axisymmetric geometry was used to approximate the three dimensional landscape of the microheater, which is modeled as a thin disk, and its surroundings, including a solid glass substrate and a fluid (air or water) environment above the substrate. The model solved 
the coupled heat transport, fluid dynamics, and molecular diffusion problems. First a temperature step was applied to the simulated microheater surface, and the model solved for local temperature, determining spatial density and viscosity values based on their tabulated temperature dependences. Convective velocities were also calculated as a function of position, based on gravity forces acting on local fluid density gradients. The result of this heat and mass transport problem was then used as the initial condition for the simulation of the electrochemical

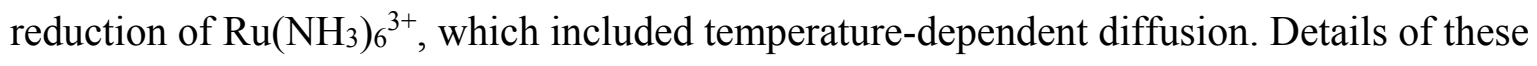
calculations are included in the Supplemental Information.

\section{Results and discussion}

\subsection{Temperature calibration}

The temperature dependence of microheaters that were deposited by e-beam evaporation in different batches (B1, B2, and B3) and microheaters with different geometries or overall spacing between the Pt microheater lines (i.e. either high or low density geometries) are compared in Fig. 2(a). The magnitude of microheater resistance, $R$, is a function of the microheater's length, $L$, and cross sectional area, $A_{C S}$, such that

$$
R=\rho_{e} \frac{L}{A_{c s}},
$$

where $\rho_{\mathrm{e}}$ is the resistivity of the conductor. The relatively large resistance of the microheaters from B1 compared to B2 and B3 is due to the longer length and smaller Pt line width (and correspondingly smaller $A_{c s}$ ) of these microheaters. In all cases, a higher density of microheater lines results in a longer microheater "wire", giving a larger resistance. Even microheaters with identical geometries, as was the case for B2, were found to have slightly different resistance magnitudes, because of differences in various contact resistances. 
Since it is arduous to independently determine the resistance magnitude $v s$. temperature of each microheater independently (particularly for these microfabricated devices, which are typically built in large arrays), the use of a more generalized calibration procedure is preferable. Fortunately, the temperature at a platinum resistance thermometer over a small temperature range can be expressed in terms of a thermal coefficient, $\alpha$, as

$$
T=\alpha^{-1}\left(\left(\alpha T_{0}+1\right) \frac{R(T)}{R\left(T_{0}\right)}-1\right),
$$

where $T_{0}$ is a reference temperature, $R\left(T_{0}\right)$ is the resistance at a reference temperature, $T_{0}$, and $R(T)$ is the resistance at the measured temperature, $T$.

Values of $\alpha$ were determined by a linear fit of $T$ vs. $R(T) / R\left(T_{0}\right)$ as shown in Fig. 2(b). Values of $\alpha$ were constant for devices fabricated within the same batch $\left(\alpha_{\mathrm{n}}=\right.$ const.), but some variation in $\alpha$ occurred between fabrication batches (B1-B3) such that $\alpha_{\mathrm{B} 1}=(3.2 \pm 0.05) \times 10^{-3}$ ${ }^{\circ} \mathrm{C}^{-1}, \alpha_{\mathrm{B} 2}=(2.5 \pm 0.01) \times 10^{-3}{ }^{\circ} \mathrm{C}^{-1}$, and $\alpha_{\mathrm{B} 3}=(2.8 \pm 0.03) \times 10^{-3}{ }^{\circ} \mathrm{C}^{-1}$. The expanded uncertainty of temperature measured with Equation 2 is primarily determined by the uncertainty in the relative resistance measurement, $R(T) / R\left(T_{0}\right)$, and is smaller than $\pm 1.5^{\circ} \mathrm{C}$ for typical measurement conditions.

The dependence of $\alpha$ on fabrication batch number suggests that $\alpha$ is mostly determined by differences in the e-beam evaporated Ti/Pt thin films that can occur during each fabrication batch's metal deposition process. Similar variations in $\alpha$ values have been observed previously in Ti/Pt thin film structures [38]. Since the Ti/Pt structures used in this work are even thinner than those described previously (100 nm thickness $v s .>700 \mathrm{~nm}$ thickness Pt layers in reference [38]), minor changes in metallic structure, interfacial mixing of the Ti and Pt layers, and impurities 
present during metal deposition might cause the lower values of $\alpha$ observed in these devices compared to that of bulk $\mathrm{Pt}\left(\alpha, \mathrm{Bulk} \mathrm{Pt}=3.85 \times 10^{-3}{ }^{\circ} \mathrm{C}^{-1}\right)[38]$.

3.2 Spatial and temporal microheater temperature distributions in the gas and solution phase

Thermal images of a microheater structure during heating in the gas and solution phase are shown in Figs. 3(a) and 3(b), respectively. As powered for this illustration, the steady-state maximum temperatures in these device images is approximately $68{ }^{\circ} \mathrm{C}$ and $37{ }^{\circ} \mathrm{C}$ in the gas and solution phases, respectively. It should be noted that these do not represent the maximum achievable temperatures, but they were chosen as representative temperatures for gas- and solution-phase applications. In both phases, the region of the surface that undergoes heating is confined almost exclusively to the area above the microheater, decaying rapidly at the edge of the microheater. Electrodes were designed with a smaller radius than the microheater to reduce the impact of the temperature gradients at the microheaters' edges and improve the temperature uniformity of the electrodes. The heated region appears to have a circular shape, because of the approximate radial symmetry of heat transport in the system. The IR imaging method used in the gas-phase measurement (Fig. 3(a)) produces a temperature image with relatively little noise compared to the fluorescent temperature imaging method, which produces images like the one shown in Fig. 3(b). The high noise in the fluorescence temperature measurements was the result of the relatively low camera sensitivity and a less elaborate gain optimization and calibration procedure compared to the pixel-wise calibration employed in the higher sensitivity IR imaging method (see Supplemental Information).

In order to visualize the development of surface temperature over time, spatiotemporal plots of temperature in space (x-axis, in the region defined by the horizontal dotted lines in Figs. 3(a) and 3(b)) and time (y-axis) are shown in Figs. 3(c) and 3(d) for gas- and solution-phase 
images, respectively. These spatiotemporal plots were generated from movies acquired during IR and fluorescent temperature imaging. The IR images used in the gas-phase measurements produced a higher quality spatiotemporal temperature representation than the fluorescent imaging used in the solution phase (Fig. 3(c) vs. 3(d)), because of the higher frame rate and lower noise in the IR measurements. The spatiotemporal plots in both the gas and solution phase are shown over the same length scale from $-0.4 \mathrm{~mm}$ to $0.4 \mathrm{~mm}$ where the center of the microheater is at $0 \mathrm{~mm}$ on the $\mathrm{x}$-axis. This spatial range was dictated by the field of view of the fluorescent measurements. Temperatures are presented at the same length scale for clearer comparison between the two phases.

The evolution of surface temperature is shown as a function of time on the $y$ axes in Figs. 3(c) and 3(d). The microheater $(280 \mu \mathrm{m} \times 260 \mu \mathrm{m})$ is powered at $t=0.3 \mathrm{~s}$ at which point the surface temperature rapidly increases. The dashed lines in Figs. 3(c) and 3(d) indicate locations and times at which the temperature is $90 \%$ of the maximum temperature. The gas phase temperature reaches a steady state within $1 \mathrm{~s}$ with a response time of $0.29 \mathrm{~s}$ obtained from an exponential fit of temperature $v s$. time. A sharp temperature gradient is apparent at the edge of the microheater near $\pm 0.18 \mathrm{~mm}$ at which point the temperature decays rapidly away from the region of the surface above the microheater. In the solution phase, the maximum temperature was reached within $1 \mathrm{~s}$. The low temporal resolution of the fluorescent images makes response time calculation unreliable, preventing a more quantitative comparison of response times in the gas and solution phase via image analysis alone. However, a more quantitative discussion of response times is given in Section 3.3, which includes results from resistance thermometry measurements. The surface temperature above the microheater appears non-uniform in the solution phase until $t \approx 2.5 \mathrm{~s}$ (dashed line in Fig. 3(d)). 
The difference in transient temperature responses in the gas and solution phase are related to the energy requirements of heating the different media. Air is more easily heated with a heat capacity of approximately $1 \mathrm{~kJ} / \mathrm{kgK} v s .4 .18 \mathrm{~kJ} / \mathrm{kgK}$ for water. The solution phase is, therefore, more resistant to temperature increase. However, the temperature profile is determined by heat transport rates, e.g. rates of thermal diffusion and convection. The lower thermal diffusivity of water compared to air $\left(\approx 1 \times 10^{-7} \mathrm{~m}^{2} / \mathrm{s}\right.$ (water) $v s . \approx 2 \times 10^{-5} \mathrm{~m}^{2} / \mathrm{s}$ (air)) might have caused the apparent delay in surface temperature uniformity observed during solution phase heating (Fig. 3(d)). To determine the extent to which the different surrounding media, air or aqueous solution, impact surface temperature uniformity, the transient thermal responses of the two systems were quantitatively modeled using FEM calculations in an approximation of the experimental system in both the gas (air) and solution (water) phases. The results of these calculations are shown in Figs. 3(e) and 3(f). Overall, the simulated thermal responses of the microheater were similar in both the gas and solution phase, suggesting that the apparent non-uniformity in the solutionphase temperature was an artifact of the relatively low resolution of the fluorescence temperature images and that the low thermal diffusivity of water did not significantly degrade the temperature uniformity and response time of microheater devices operated in the solution phase.

\subsection{Thermal crosstalk between adjacent sensors}

Assessing the extent of thermal interactions (or crosstalk) between adjacent microheaters is crucial to the future realization of large scale arrays of heated sensors for high throughput screening applications. Although thermal crosstalk can be eliminated by increasing separation distances, minimally spaced sensors are desirable to realize sensor array devices with a small footprint for future high throughput sensing applications. Chemical crosstalk between adjacent sensors was assessed for gas-phase sensors by monitoring changes in signal quality in response 
to temperature changes at an adjacent microheater [39]. In the current work, thermal crosstalk was determined by monitoring the temperature near a powered microheater in a similar approach to that used in reference [27]. The experimental approach is depicted in Fig. 4(a), which shows a heated microheater (a) and two adjacent resistance thermometers (b and $\mathbf{c}$ ), which in practice are two microheaters operated at low current to minimize self-heating (see Section 2.5).

Thermometers $\mathbf{b}$ and $\mathbf{c}$ are located $0.5 \mathrm{~mm}$ and $1 \mathrm{~mm}$ away from a, respectively. Although this approach neglects any possible chemical crosstalk, the measurement of temperature changes alone enables a direct comparison of microheaters in the gas and solution phase.

Figs. 4(c) and 4(d) show the temperatures at $\mathbf{a}, \mathbf{b}$ and $\mathbf{c}$ during heating at $\mathbf{a}$ in both the gas and solution phase, respectively. In this case, a was powered at $5 \mathrm{~mA}$ in both the gas and solution phase. The temperature obtained in the gas phase is higher than in the solution phase, because water's larger heat capacity decreases heating efficiency. In both phases a small but nonnegligible increase in temperature occurs at both adjacent sensor positions as in the insets in Figs. $4(\mathrm{c})$ and $4(\mathrm{~d})$. At steady state in the gas phase, $T_{a}=57.2^{\circ} \mathrm{C}, T_{b}=26.3{ }^{\circ} \mathrm{C}$ and $T_{c}=24.6{ }^{\circ} \mathrm{C}$, while in the solution phase $T_{a}=48.0^{\circ} \mathrm{C}, T_{b}=24.1^{\circ} \mathrm{C}$, and $T_{c}=23.2{ }^{\circ} \mathrm{C}$. These temperatures correspond to a relative temperature change at $\mathbf{b}$ and $\mathbf{c}$, respectively, of $14 \%$ and $9.2 \%$ for the gas phase and $10 \%$ and $7.1 \%$ for the solution phase.

The transient temperature responses at $\mathbf{b}$ and $\mathbf{c}$ contain information about the relative time scales of thermal transport in the gas and solution phase. For instance, thermal transients can be described by a circuit model (Fig. 4(b)). This model implies a thermal time constant, $\tau$, given by

$$
\tau=R_{\mathrm{a}-\mathrm{i}} C_{\mathrm{a}-\mathrm{i}},
$$


where $\mathbf{i}=\mathbf{b}$ or $\mathbf{c}$ and and $R_{a-i}$ and $C_{a-i}$ are the thermal resistance and capacitance between positions a and $\mathbf{i}$, respectively. The thermal time constant can be extracted from temperature, $T$, $v s$. time, $t$, curves using

$$
T=T_{0}+\Delta T(1-\exp (-t / \tau),
$$

where $T_{0}$ is the initial temperature $\left(21.3{ }^{\circ} \mathrm{C}\right)$ and $\Delta T$ is the change in temperature after long times $\left(t \geq 50 \mathrm{~s}\right.$ ). Values of the thermal time constant for the gas and solution phases, $\tau_{\mathrm{gas}}$ and $\tau_{\mathrm{sol}}$, at a, $\mathbf{b}$, and $\mathbf{c}$ are $\tau_{\mathrm{gas}, \mathrm{a}}=0.91 \mathrm{~s}, \tau_{\mathrm{gas}, \mathrm{b}}=2.7 \mathrm{~s}, \tau_{\mathrm{gas}, \mathrm{c}}=5.5 \mathrm{~s}, \tau_{\mathrm{sol}, \mathrm{a}}=1.0 \mathrm{~s}, \tau_{\mathrm{sol}, \mathrm{b}}=3.2 \mathrm{~s}$, and $\tau_{\mathrm{sol}, \mathrm{c}}=10.5 \mathrm{~s}$. The time constants at a are an indication of how long it took the microheater to reach stable temperatures. In both phases, a stable temperature was reached within $<2 \mathrm{~s}$, just as rapid as the temperature steps achieved by directly heated hot wire electrodes [40]. The microheaters experienced small positive temperature drifts of approximately $0.006{ }^{\circ} \mathrm{C} / \mathrm{s}$ and $0.005{ }^{\circ} \mathrm{C} / \mathrm{s}$ in the gas and solution phases, respectively. These slow rises in temperature, which were likely the result of positive feedback between resistance rise and power output in the microheater, led to negligible changes in temperature on the time scale $(<1 \mathrm{~min})$ of the electrochemical measurements described in Section 3.4.

FEM calculations were used to model heat transfer in the multicomponent microheater system. Simulation results are plotted in the insets to Figs. 4(c) and 4(d) (dashed lines) and are in good agreement with the experimental results. This agreement of simulation with experiment validates the accuracy of these calculations, which were also central to the interpretation of thermal images (Section 3.2) and electrochemical signals (Section 3.4). 


\subsection{Microheater-controlled electrochemical measurements}

The OCP of a heated electrode ( $v s . \mathrm{Ag} / \mathrm{AgCl})$ was measured at different temperatures in a solution containing $0.5 \mathrm{~mol} / \mathrm{L} \mathrm{KNO}_{3}, 0.2 \mathrm{~mol} / \mathrm{L}$ potassium phosphate buffer $(\mathrm{pH} 7)$, and 10 $\mathrm{mmol} / \mathrm{L} \mathrm{K} 3\left[\mathrm{Fe}(\mathrm{CN})_{6}\right] / \mathrm{K}_{3}\left[\mathrm{Fe}(\mathrm{CN})_{6}\right](1: 1)$. Changes in electrode temperature were calculated from shifts in the OCP using the established temperature coefficient of $1.56 \mathrm{mV} /{ }^{\circ} \mathrm{C}[40]$. Fig. 5(a) shows a plot of the temperature calculated from OCP measurements, TOCP, vs. the temperature determined from the microheater's resistance, $T_{R}$. The slope of $T_{O C P} v S . T_{R}$ was approximately 1.02 , indicating that the temperature at the electrode surface was very near to the temperature at the proximally located microheater. The small deviation of this slope from one, which would result in a temperature difference between $T_{O C P}$ and $T_{R}$ of only $1{ }^{\circ} \mathrm{C}$ at $T_{R}=50 \mathrm{oC}$, was within the error of the individual temperature measurements described above.

In order to determine the effect of temperature on an analytical signal (i.e., electrochemical current), cyclic voltammograms were recorded at $100 \mathrm{mV} / \mathrm{s}$ in $0.5 \mathrm{~mol} / \mathrm{L} \mathrm{KNO}_{3}$, $0.2 \mathrm{~mol} / \mathrm{L}$ phosphate buffer $(\mathrm{pH} 7)$, and $10 \mathrm{mmol} / \mathrm{L} \mathrm{Ru}\left(\mathrm{NH}_{3}\right)_{6} \mathrm{Cl}_{3}$ at different temperatures $(21.3$ ${ }^{\circ} \mathrm{C}, 51.6{ }^{\circ} \mathrm{C}, 64.4{ }^{\circ} \mathrm{C}, 72.5^{\circ} \mathrm{C}$, and $81.5^{\circ} \mathrm{C}$ ) as shown in Fig. 5 (a). Current magnitude for the reduction of $\mathrm{Ru}\left(\mathrm{NH}_{3}\right)_{6} \mathrm{Cl}_{3}$ increases when the temperature is increased. The shapes of the cyclic voltammograms also transitioned from peak-shaped to approximately sigmoidal at higher temperatures. Both the increased current magnitude and the shift in curve shape indicate enhanced transport of electroactive species to the electrode surface and have been observed with other heated electrodes $[41,42]$.

A plot of peak current at temperature, $T$, relative to the peak current at $T_{0}$ is given in Fig. 5(b) (solid squares). This relative current, given by $i(T) / i\left(T_{0}\right)$, is a measure of signal enhancement. At the highest temperature of $81.5^{\circ} \mathrm{C}$, for example, the electrochemical signal 
enhancement is $\approx 3 \times$. For comparison, the expected signal enhancement was calculated analytically using the dependence of the peak current on the square root of the temperaturedependent diffusion coefficient [43], $D(T)$, which is given by

$$
D(T)=D_{0} \exp \left(\frac{E_{a}}{R}\left(\frac{1}{T_{0}}-\frac{1}{T}\right)\right),
$$

where $D_{0}$ is the diffusion coefficient at $T_{0}, E_{a}(22.5 \mathrm{~kJ} / \mathrm{mol}[44])$ is the activation energy of diffusion for $\mathrm{Ru}\left(\mathrm{NH}_{3}\right)_{6} \mathrm{Cl}_{3}$, and $R(8.314 \mathrm{~J} / \mathrm{molK})$ is the universal gas constant. The calculated signal enhancement is shown in Fig. 5(b) (solid line). These calculated values are lower than those observed experimentally, suggesting that an additional, temperature-dependent transport mechanism may be enhancing the signal beyond that achieved through diffusion alone.

Since thermal convection is neglected in the analytical solution described above, FEM calculations were used to explore its impact on signal enhancement. In order to first validate the model's performance, calculations were performed in the absence of thermal convection. These results were in good agreement with the analytical solution as shown in Fig. 5(b) (No Convection). With thermal convection, signal enhancement increased markedly as shown in Fig. 5(b) (Convection), demonstrating the important signal-enhancing role of thermal convection. FEM results are slightly higher than those observed experimentally, indicating that the rate of thermal convection in the real system is lower than the calculated value. This discrepancy is most likely caused by interfacial effects around the small fluid volume used in experiments $(\approx 40 \mu \mathrm{L})$, which are not accounted for in the model. 


\section{Conclusions}

Multilayer microfabricated devices for temperature-controlled sensing in the solution phase were fabricated consisting of gold disk electrodes with underlying platinum microheater elements. Following temperature calibrations, combined thermal imaging, transient temperature measurements at adjacent microheaters, and theoretical FEM calculations were used to characterize surface temperature distributions and thermal response times of the microheater devices. Solution-phase heating was sufficiently uniform and rapid to enable studies of the temperature-dependent electrochemistry of a model analyte, $\mathrm{Ru}\left(\mathrm{NH}_{3}\right)_{6} \mathrm{Cl}_{3}$, which experienced a signal enhancement of $\approx 3 \times$ at $81.5^{\circ} \mathrm{C}$. This signal enhancement, which was higher than that predicted by an analytical approximation based on diffusion alone, was explained using FEM calculations that accounted for both diffusion and thermal convection near the heated electrode surface. This characterization of $\mathrm{Ru}\left(\mathrm{NH}_{3}\right)_{6} \mathrm{Cl}_{3}$, which primarily undergoes transport-controlled electrochemistry, will act as a foundation for future studies of more complex biochemical systems involving enzymes, antibodies, and DNA, which display temperature-dependent activities, affinities, and melting characteristics. Meanwhile, the thermal characterization procedures established in this work will guide the development of sensor arrays for highthroughput, (bio)chemical studies using transient temperature programs like those proven successful in gas-phase studies.

\section{Acknowledgements}

NMC acknowledges funding from the National Research Council's National Institute of Standards and Technology (NIST) Postdoctoral Associateship Program. We thank M. Carrier and C. Montgomery for helpful discussion and assistance with microfabrication tools and techniques. We acknowledge support from the Center for Nanoscale Science and Technology's 
Nanofab at NIST. We also thank B. Lane of NIST's Intelligent Systems Division for assistance with IR thermal imaging and suggestion of the IR temperature calibration method used in this work.

*Certain trade names and company products have been identified in order to adequately specify the experimental procedure. In no case does such identification imply recommendation or endorsement by the National Institute of Standards and Technology, nor does it imply that the products are necessarily the best for the purpose.

\section{References}

[1] M. Graf, A. Gurlo, N. Bârsan, U. Weimar, A. Hierlemann, Microfabricated gas sensor systems with sensitive nanocrystalline metal-oxide films, J. Nanoparticle Res. 8 (2006) 823-839. doi:10.1007/s11051-005-9036-7.

[2] I. Simon, N. Bârsan, M. Bauer, U. Weimar, Micromachined metal oxide gas sensors: Opportunities to improve sensor performance, Sensors Actuators, B Chem. 73 (2001) 126. doi:10.1016/S0925-4005(00)00639-0.

[3] S. Semancik, R.E. Cavicchi, M.C. Wheeler, J.E. Tiffany, G.E. Poirier, R.M. Walton, et al., Microhotplate platforms for chemical sensor research, Sensors Actuators, B Chem. 77 (2001) 579-591. doi:10.1016/S0925-4005(01)00695-5.

[4] J.S. Suehle, R.E. Cavicchi, M. Gaitan, S. Semancik, Tin oxide gas sensor fabricated using CMOS micro-hotplates and in-situ processing, IEEE Electron Device Lett. 14 (1993) 118120. doi: $10.1109 / 55.215130$.

[5] S.K.H. Fung, P.C.H. Chan, J.K.O. Sin, P.W. Cheung, Design and fabrication of microhotplate for thin film gas sensor, 1994 IEEE Hong Kong Electron Devices Meet. (1994) 44-47. doi:10.1109/HKEDM.1994.395133.

[6] R.E. Cavicchi, J.S. Suehle, K.G. Kreider, M. Gaitan, P. Chaparala, Fast Temperature Programmed Sensing for Micro-Hotplate Gas Sensors, IEEE Electron Device Lett. 16 (1995) 286-288. doi:10.1109/55.790737.

[7] Cambridge CMOS Sensors, www.ccmoss.com (accessed August 6, 2015).

[8] D.C. Meier, J.K. Evju, Z. Boger, B. Raman, K.D. Benkstein, C.J. Martinez, et al., The potential for and challenges of detecting chemical hazards with temperature-programmed 
microsensors, Sensors Actuators, B Chem. 121 (2007) 282-294.

doi:10.1016/j.snb.2006.09.050.

[9] K.D. Mitzner, J. Sternhagen, D.W. Galipeau, Development of a micromachined hazardous gas sensor array, Sensors Actuators, B Chem. 93 (2003) 92-99. doi:10.1016/S09254005(03)00244-2.

[10] L. Francioso, A. Forleo, A.M. Taurino, P. Siciliano, L. Lorenzelli, V. Guarnieri, et al., Linear temperature microhotplate gas sensor array for automotive cabin air quality monitoring, Sensors Actuators, B Chem. 134 (2008) 660-665. doi:10.1016/j.snb.2008.06.008.

[11] M. Graf, U. Frey, S. Taschini, A. Hierlemann, Micro hot plate-based sensor array system for the detection of environmentally relevant gases, Anal. Chem. 78 (2006) 6801-6808. doi:10.1021/ac060467d.

[12] B. Raman, J.L. Hertz, K.D. Benkstein, S. Semancik, Bioinspired methodology for artificial olfaction, Anal. Chem. 80 (2008) 8364-8371. doi:10.1021/ac8007048.

[13] K.D. Benkstein, B. Raman, C.B. Montgomery, C.J. Martinez, S. Semancik, Microsensors in Dynamic Backgrounds: Toward Real-Time Breath Monitoring, IEEE Sens. J. 10 (2010) 137-144. doi:10.1109/JSEN.2009.2035738.

[14] P.H. Rogers, S. Semancik, Feedback-enabled discrimination enhancement for temperature-programmed chemiresistive microsensors, Sensors Actuators, B Chem. 158 (2011) 111-116. doi:10.1016/j.snb.2011.05.051.

[15] B. Raman, R. Shenoy, D.C. Meier, K.D. Benkstein, C. Mungle, S. Semancik, Detecting and recognizing chemical targets in untrained backgrounds with temperature programmed sensors, IEEE Sens. J. 12 (2012) 3238-3247. doi:10.1109/JSEN.2012.2197196.

[16] P.H. Rogers, K.D. Benkstein, S. Semancik, Machine learning applied to chemical analysis: Sensing multiple biomarkers in simulated breath using a temperature-pulsed electronic-nose, Anal. Chem. 84 (2012) 9774-9781. doi:10.1021/ac301687j.

[17] J. Li, G.P. Peterson, Microscale heterogeneous boiling on smooth surfaces-from bubble nucleation to bubble dynamics, Int. J. Heat Mass Transf. 48 (2005) 4316-4332. doi:10.1016/j.ijheatmasstransfer.2005.05.022.

[18] R.E. Cavicchi, C.T. Avedisian, Bubble nucleation and growth anomaly for a hydrophilic microheater attributed to metastable nanobubbles, Phys. Rev. Lett. 98 (2007) 23-26. doi:10.1103/PhysRevLett.98.124501.

[19] D. Lee, S.H. Park, H. Yang, K. Chung, T.H. Yoon, K. Kim, et al., Bulk-micromachined submicroliter-volume PCR chip with very rapid thermal response and low power consumption, (2004) 401-407. doi:10.1039/B313547K. 
[20] C.-M. Chang, W.-H. Chang, C.-H. Wang, J.-H. Wang, J.D. Mai, G.-B. Lee, Nucleic acid amplification using microfluidic systems, Lab Chip. 13 (2013) 1225-42. doi:10.1039/c3lc41097h.

[21] C. Zhang, J. Xu, W. Ma, W. Zheng, PCR microfluidic devices for DNA amplification, Biotechnol. Adv. 24 (2006) 243-284. doi:10.1016/j.biotechadv.2005.10.002.

[22] A. Jain, K. Ness, K.E. Goodson, Theoretical and experimental investigation of spatial temperature gradient effects on cells using a microfabricated microheater platform, Sensors Actuators, B Chem. 143 (2009) 286-294. doi:10.1016/j.snb.2009.08.035.

[23] W. Shu, W.N. Everett, Q.X. Zhang, M.H. Liu, A. Trigg, Y. Ma, et al., Microheated substrates for patterning cells and controlling development, J. Microelectromechanical Syst. 14 (2005) 924-934. doi:10.1109/JMEMS.2005.856677.

[24] S.-M. Park, J.-Y. Ahn, M. Jo, D.-K. Lee, J.T. Lis, H.G. Craighead, et al., Selection and elution of aptamers using nanoporous sol-gel arrays with integrated microheaters, Lab Chip. 9 (2009) 1206-1212. doi:10.1039/b814993c.

[25] H.F. Arata, Y. Rondelez, H. Noji, H. Fujita, Temperature alternation by an on-chip microheater to reveal enzymatic activity of beta-galactosidase at high temperatures, Anal. Chem. 77 (2005) 4810-4814. doi:10.1021/ac050385+.

[26] H.F. Arata, F. Gillot, D. Collard, H. Fujita, Millisecond analysis of double stranded DNA with fluorescent intercalator by micro-thermocontrol-device, Talanta. 79 (2009) 963-6. doi:10.1016/j.talanta.2009.04.045.

[27] H. Yang, C.A. Choi, K.H. Chung, C.H. Jun, Y.T. Kim, An Independent, TemperatureControllable Microelectrode Array, Anal. Chem. 76 (2004) 1537-1543.

doi:10.1021/ac035270p.

[28] Z. Shen, H.O. Sintim, S. Semancik, Rapid nucleic acid melting analyses using a microfabricated electrochemical platform, Anal. Chim. Acta. 853 (2015) 265-270. doi:10.1016/j.aca.2014.10.025.

[29] P. Gründler, A. Kirbs, L. Dunsch, Modern thermoelectrochemistry, Chemphyschem. 10 (2009) 1722-46. doi:10.1002/cphc.200900254.

[30] B. Miller, Thermal Modulation Voltammetry, J. Electrochem. Soc. 130 (1983) 1639. doi:10.1149/1.2120054.

[31] M. a. Slifkin, I. Bakarudin, Relaxation studies of polyvalent and monovalent electrolytes using a modulated heating technique, Electrochim. Acta. 30 (1985) 907-911.

doi:10.1016/0013-4686(85)80148-1. 
[32] Y.C. Tsai, B.A. Coles, R.G. Compton, F. Marken, Microwave activation of electrochemical processes: Enhanced electrodehalogenation in organic solvent media, J. Am. Chem. Soc. 124 (2002) 9784-9788. doi:10.1021/ja026037w.

[33] P. Gründler, Theory and practice of sensors with hot-wire electrodes, Fresenius. J. Anal. Chem. (1998) 180-183. doi:10.1007/s002160051055.

[34] G.-U. Flechsig, A. Walter, Electrically Heated Electrodes: Practical Aspects and New Developments, Electroanalysis. 24 (2012) 23-31. doi:10.1002/elan.201100412.

[35] P. Gründler, G.-U. Flechsig, Principles and Analytical Applications of Heated Electrodes, Microchim. Acta. 154 (2006) 175-189. doi:10.1007/s00604-006-0512-2.

[36] Gensoric, www.gensoric.com (accessed August 6, 2015).

[37] R. Fu, B. Xu, D. Li, Study of the temperature field in microchannels of a PDMS chip with embedded local heater using temperature-dependent fluorescent dye, Int. J. Therm. Sci. 45 (2006) 841-847. doi:10.1016/j.ijthermalsci.2005.11.009.

[38] K.G. Kreider, D.C. Ripple, W. a Kimes, Thin-film resistance thermometers on silicon wafers, Meas. Sci. Technol. 20 (2009) 045206. doi:10.1088/0957-0233/20/4/045206.

[39] M.C. Wheeler, J.E. Tiffany, R.M. Walton, R.E. Cavicchi, S. Semancik, Chemical crosstalk between heated gas microsensor elements operating in close proximity, Sensors Actuators, B Chem. 77 (2001) 167-176. doi:10.1016/S0925-4005(01)00689-X.

[40] T. Zerihun, P. Gründler, Electrically heated cylindrical microelectrodes. The reduction of dissolved oxygen on Pt, J. Electroanal. Chem. 404 (1995) 243-248. doi:10.1016/00220728(95)04390-X.

[41] P. Gründler, A. Beckmann, Hydrodynamics with heated microelectrodes, Anal. Bioanal. Chem. 379 (2004) 261-5. doi:10.1007/s00216-004-2535-z.

[42] J. Krejci, Z. Sajdlova, T. Marvanek, Voltammetry under a controlled temperature gradient, Sensors (Basel). 10 (2010) 6821-35. doi:10.3390/s100706821.

[43] A.J. Bard, L.R. Faulkner, Electrochemical methods: fundamentals and applications, 2001. doi:10.1016/j.aca.2010.06.020.

[44] F. Qiu, R.G. Compton, B. a Coles, F. Marken, Thermal activation of electrochemical processes in a Rf-heated channel flow cell: experiment and finite element simulation, 492 (2000) 150-155. doi:10.1016/S0022-0728(00)00222-9. 


\section{Figure Captions}

Fig. 1. (a) Schematic diagram of heated electrode fabrication procedure, which includes (i) patterning microheater and electrical contact structures in AZ5214, (ii) depositing Ti/Pt, (iii) lifting off photoresist, (iv) depositing insulating $\mathrm{SiO}_{2}$ layer, (v) patterning electrode and electrical contact structures, (vi) depositing electrode metal, $\mathrm{Ti} / \mathrm{Au}$, (vii) lifting off photoresist, (viii) depositing insulating $\mathrm{SiO}_{2}$ layer, (ix) patterning exposed electrode and electrical contact regions in $\mathrm{S} 1813$ photoresist, and (x) etching $\mathrm{SiO}_{2}$ to expose active electrode areas and contact pads. (b) Micrograph of a spiral-shaped microheater. (c) Micrograph of complete structure with electrochemical sensor and underlying microheater.

Fig. 2. (a) Resistance vs. temperature for thin film Pt microheaters that were e-beam deposited during different fabrication runs. Three different microheater depositions (B1-B3) are indicated by $\boldsymbol{\Delta}(\mathrm{B} 1), \bullet(\mathrm{B} 2)$, and $\mathbf{\boldsymbol { a }}(\mathrm{B} 3)$. Two different microheater geometries were designed into the B1 and B3 devices with high and low densities of microheater lines as indicated by the figure labels. (b) Temperature vs. normalized microheater resistance for the same data presented in A. Error bars (shown more clearly in the inset to (b))indicate the standard deviation of measurements on different devices $(n \geq 3)$ deposited on the same substrate.

Fig. 3. Thermal images of a powered microheater device in the gas (a) and solution (b) phases recorded using IR and fluorescent imaging, respectively. Spatio-temporal temperature plots derived from temperature measurements taken over time in the gas (c) and solution (d) phases within the regions marked by the dashed lines in (a) and (b). Simulated spatio-temporal temperature plots for the same microheater geometry in the gas (e) and solution (f) phases.

Fig. 4. (a) Depiction of adjacent microheaters/resistance temperature thermometers such that position $\mathbf{a}$ is heated while temperature is monitored at positions $\mathbf{b}$ and c. (b) Equivalent circuit diagram for analysis of the time dependent temperature at each location. (c, d) Experimental (solid) and simulated (dashed) temperatures at each position as a function of time in the gas (c) and solution (d) phase.

Fig. 5. (a) Cyclic voltammograms at a gold disk electrode in $0.5 \mathrm{~mol} / \mathrm{L} \mathrm{KNO}_{3}, 0.2 \mathrm{~mol} / \mathrm{L}$

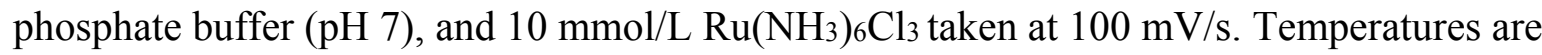
given in legend. Unlabeled dashed line is the current in the absence of $\mathrm{Ru}\left(\mathrm{NH}_{3}\right)_{6} \mathrm{Cl}_{3}$. (b) Relative current as a function of microheater temperature for experimental, analytical, and simulated results. Simulations were performed with and without convection. Symbols are defined in the legend. The horizontal dashed line at $i(T) / i\left(T_{0}\right)=1$ is included for comparison. 
Black and White Figures

(a) $\mathrm{i}$

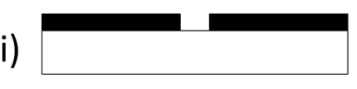

ii)

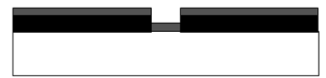

iii)

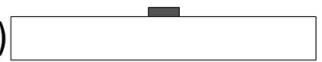

iv)

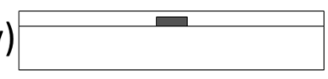

v)

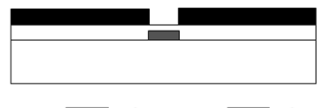

$\square$ Glass vi)

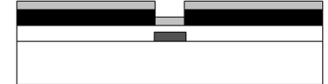

vii)

viii)

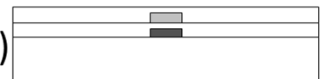

ix)

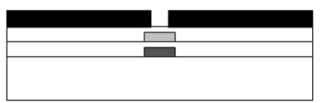

x)

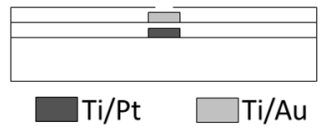

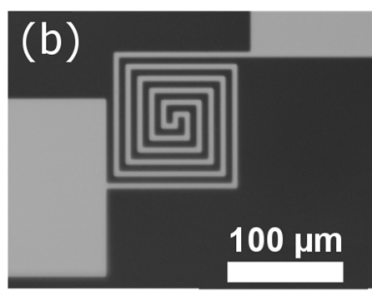

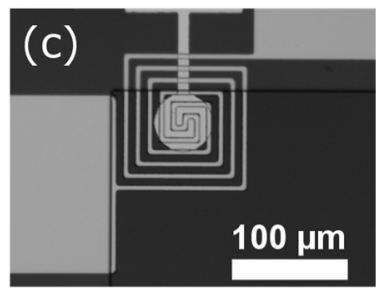

Fig. 1.
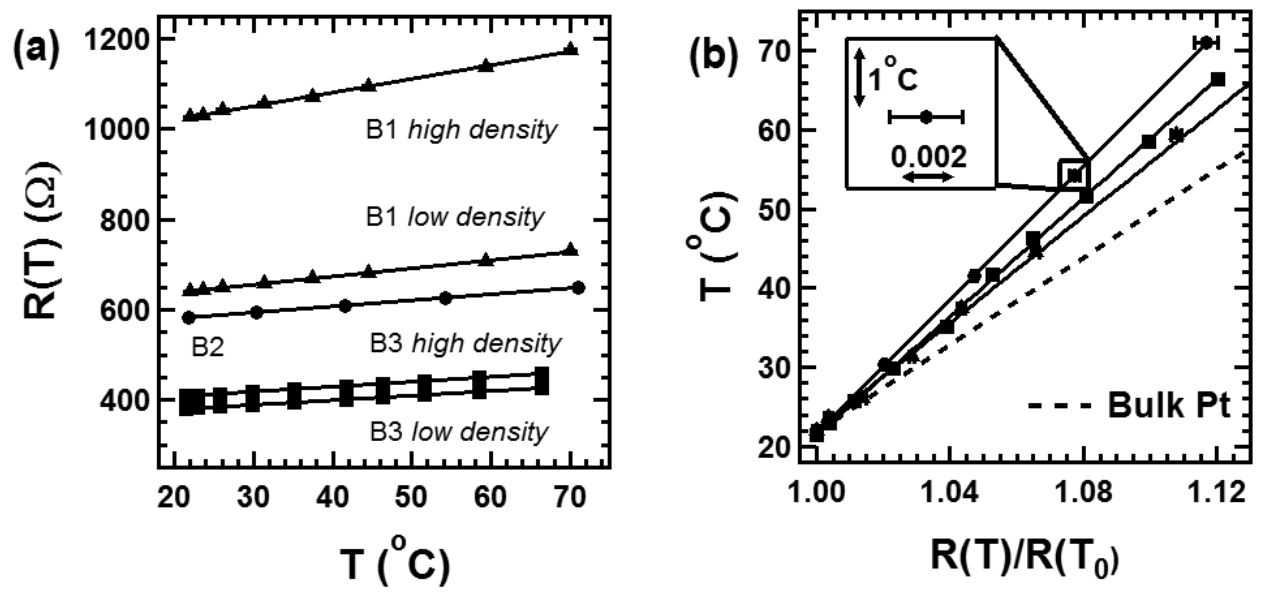

Fig. 2. 

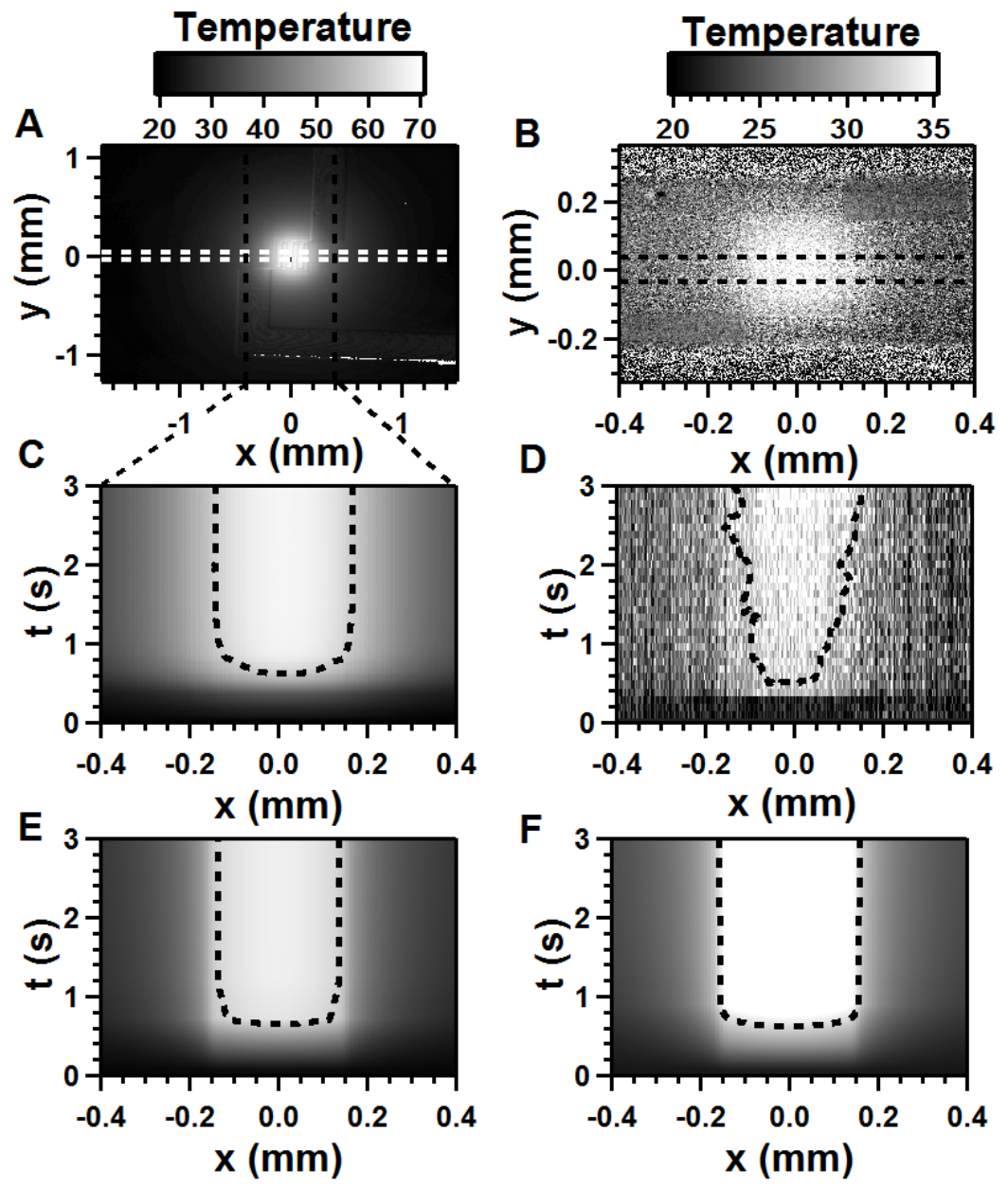

Fig. 3. 
(a)
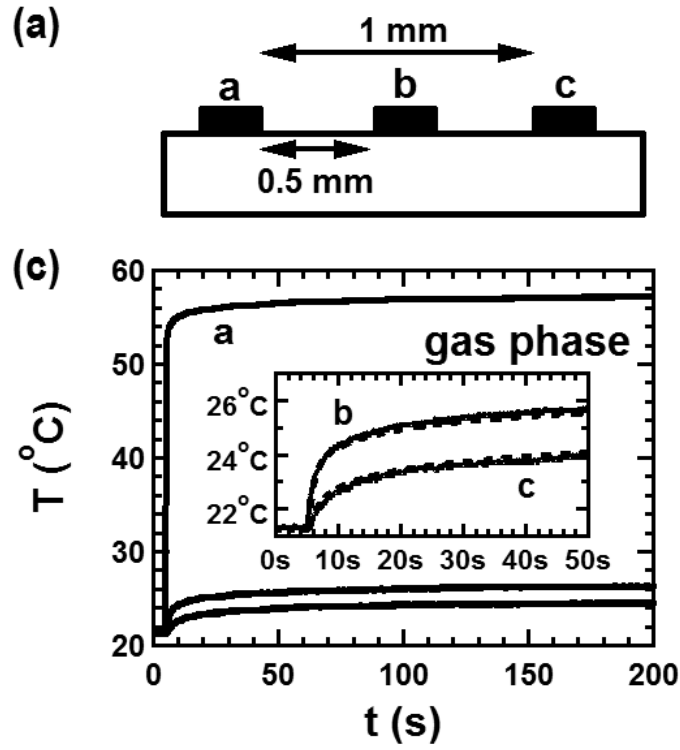

(b)
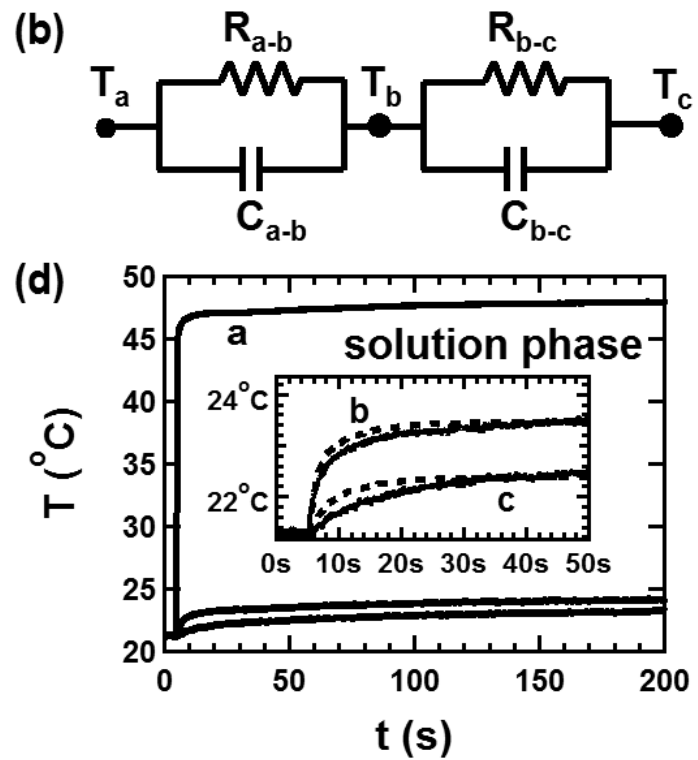

Fig. 4. 

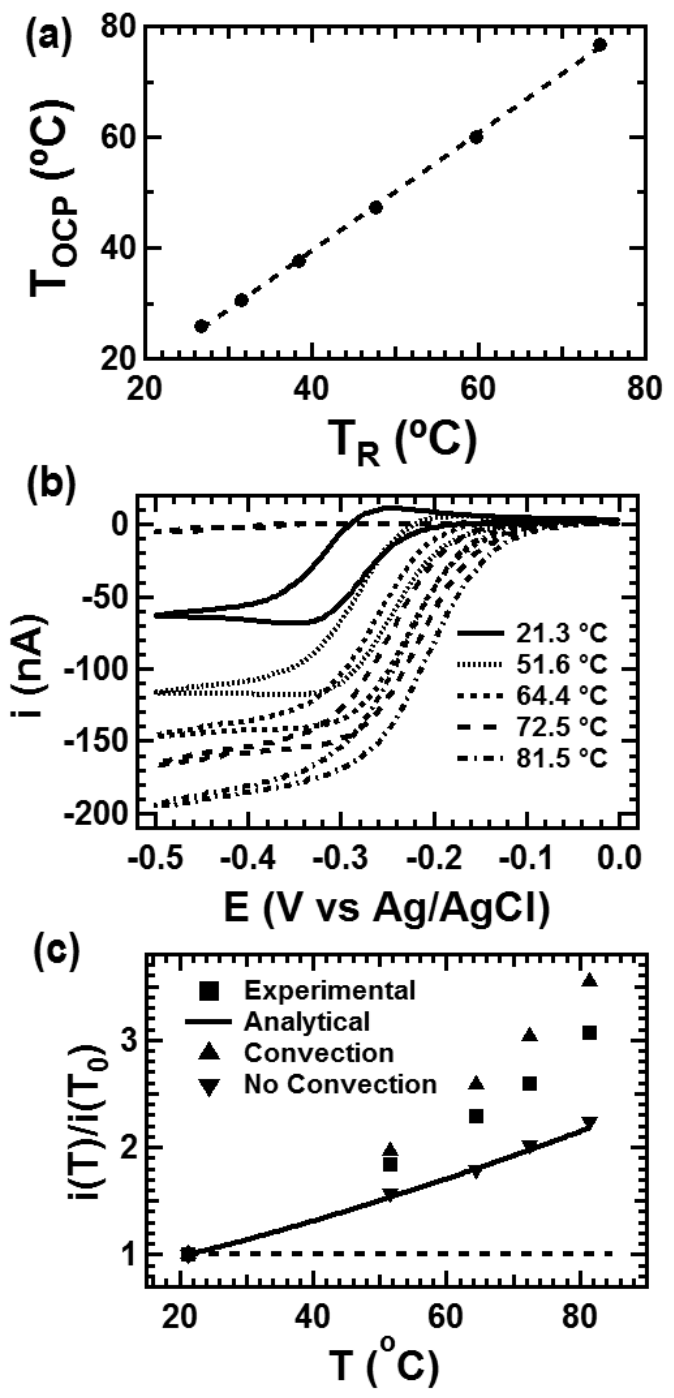

Fig. 5. 


\section{Color Figures}

(a) $\mathrm{i}$

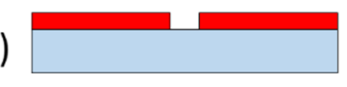

ii)

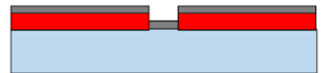

iii)

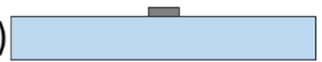

iv)

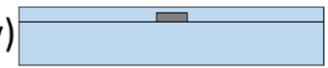

v)

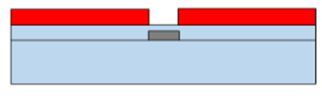

$\square$ Glass vi)

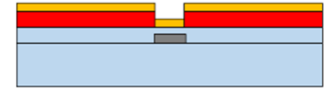

vii)

viii)

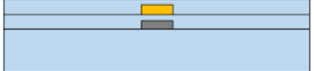

ix)

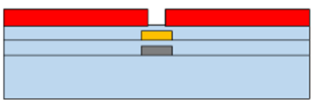

x)

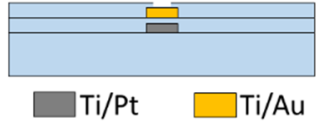

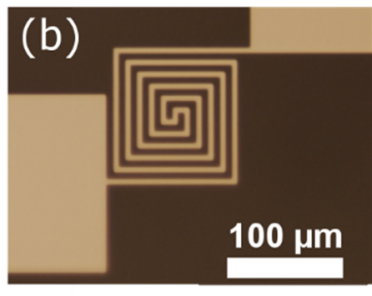

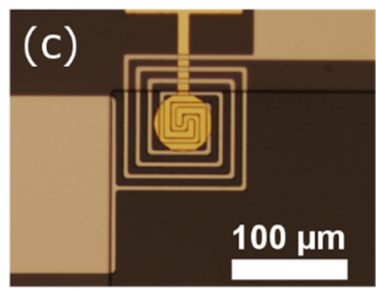

Fig. 1.
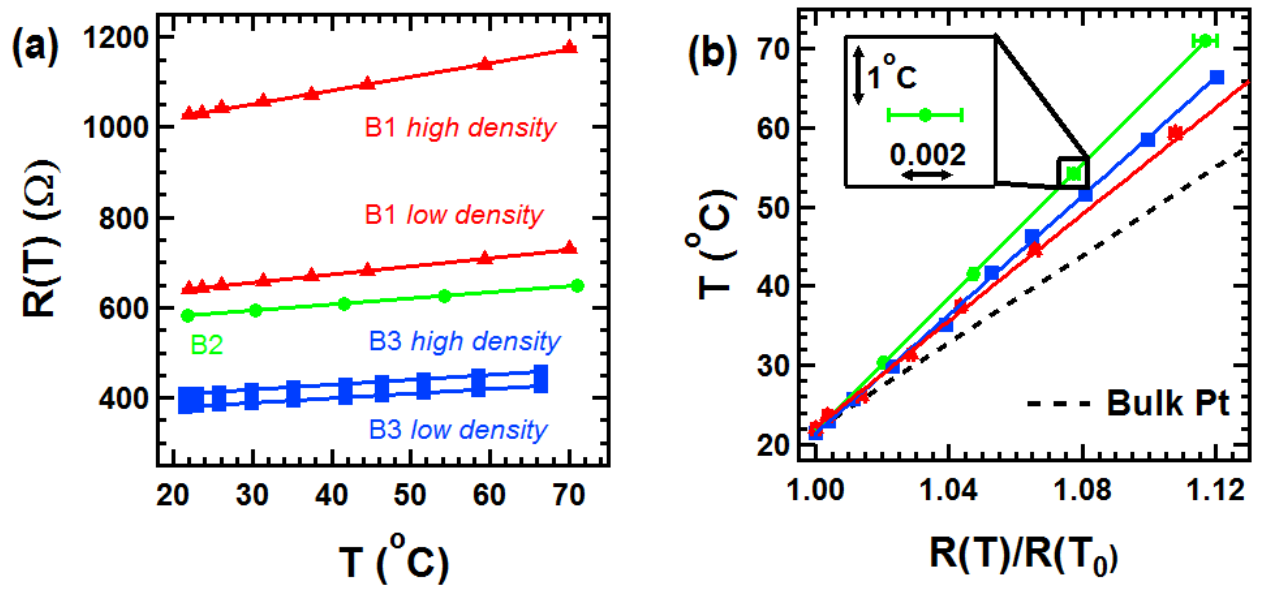

Fig. 2. 

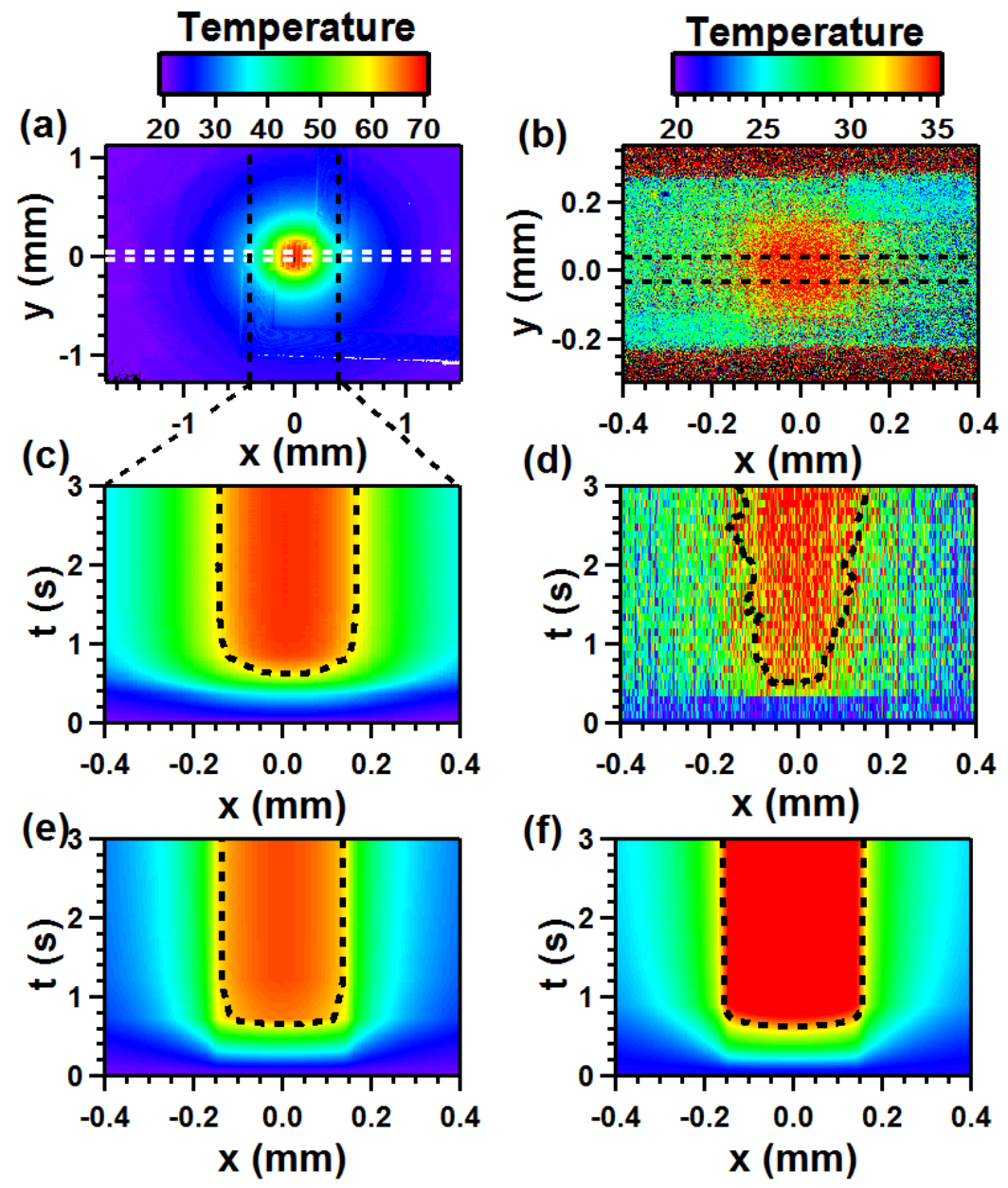

Fig. 3. 
(a)
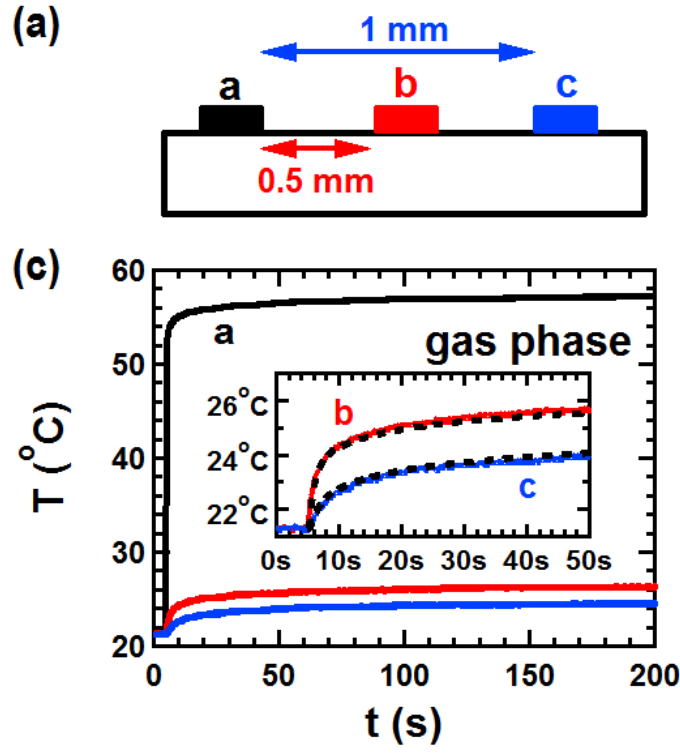

(b)
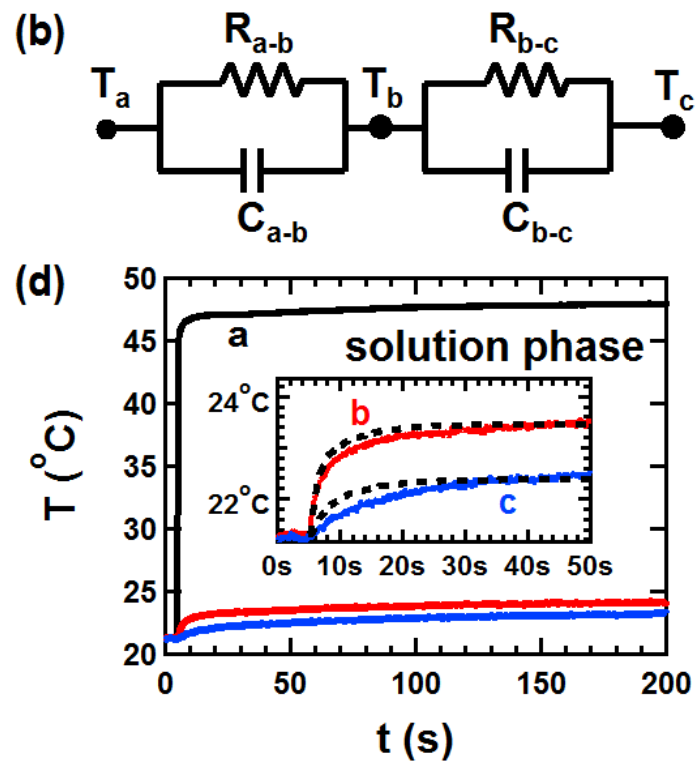

Fig. 4. 

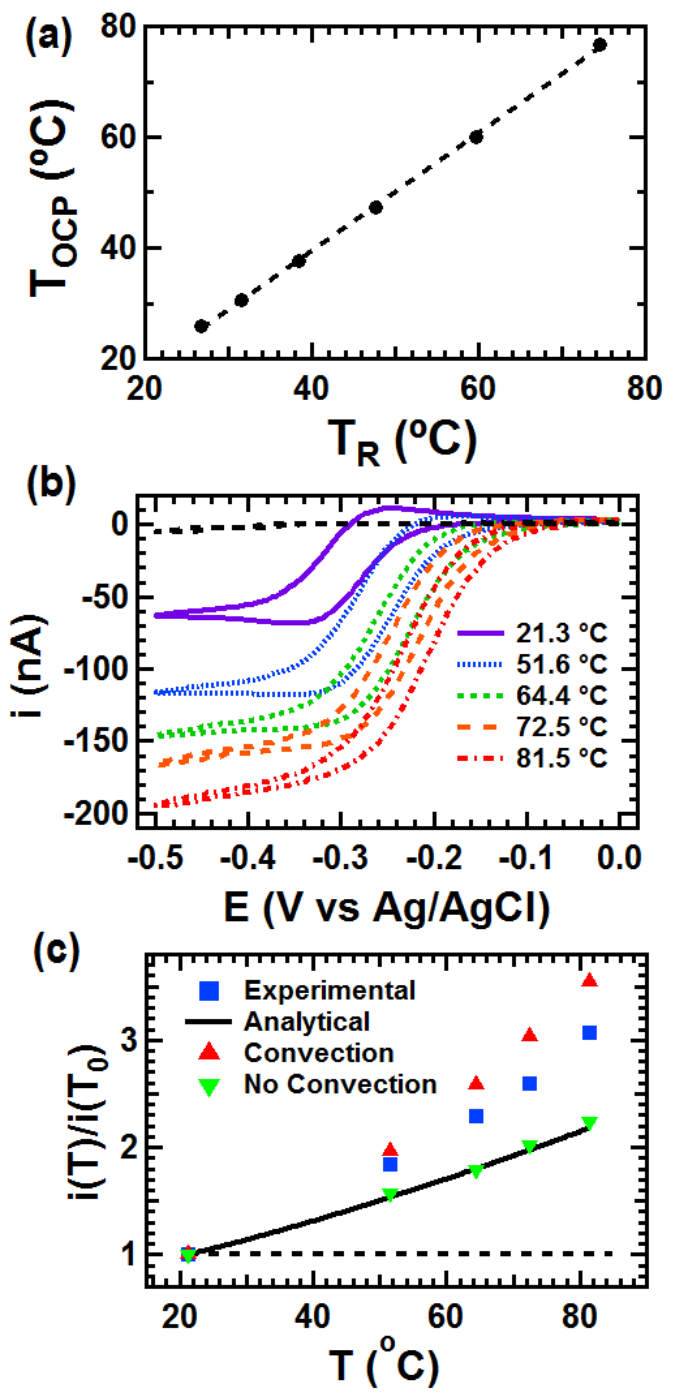

Fig. 5. 


\section{Graphical abstract}

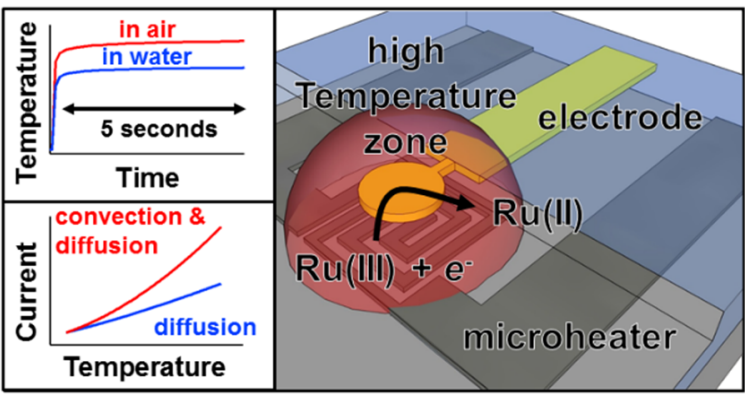




\section{Vitae}

N. Contento received his B.S degree in Chemical Engineering in 2009 from the University of Florida and his Ph.D. in Chemical and Biomolecular Engineering in 2014 from the University of Notre Dame. He is currently a National Research Council Postdoctoral Associate in the Biomolecular Measurement Division at the National Institute of Standards and Technology (NIST).

S. Semancik is the Project Leader of the Chemical Microsensor Program at the National Institute of Standards and Technology (NIST) in Gaithersburg, Maryland. He received his B.S. degree in physics from Rensselaer Polytechnic Institute and his Sc.M. and Ph.D. degrees, also in physics, from Brown University. Dr. Semancik's professional research career began as a National Research Council Postdoctoral Associate, and has been centered in the fields of surface science and sensor science. His recent work has focused on developing improved nanomaterials for chemical and biochemical sensing, and combining such high performance materials with micromachined platforms to realize advanced microsensor devices and operating modes. He has authored or coauthored more than 150 papers, including multiple reviews, several book chapters, and five patents. Dr. Semancik is an elected Fellow of both the American Physical Society and the American Vacuum Society, has served as a Member of the Editorial Board of two sensor journals, and is a Member of the Steering Committee of the International Meeting on Chemical Sensors. 